Linguistique, littérature, didactique

\title{
Questions aux linguistes d'aujourd'hui sur poésie, langue et didactique
}

\section{Michel Favriaud}

\section{(2) OpenEdition}

\section{Journals}

\section{Édition électronique}

URL : http://journals.openedition.org/pratiques/4901

DOI : 10.4000/pratiques.4901

ISSN : 2425-2042

\section{Éditeur}

Centre de recherche sur les médiations (CREM)

\section{Référence électronique}

Michel Favriaud, «Questions aux linguistes d'aujourd'hui sur poésie, langue et didactique », Pratiques [En ligne], 179-180 | 2018, mis en ligne le 31 décembre 2018, consulté le 20 avril 2019. URL : http:// journals.openedition.org/pratiques/4901; DOI : 10.4000/pratiques.4901

Ce document a été généré automatiquement le 20 avril 2019.

(c) Tous droits réservés 


\title{
Questions aux linguistes d'aujourd'hui sur poésie, langue et didactique
}

\author{
Michel Favriaud
}

1 1. Quelle place tient la poésie dans vos lectures, dans votre vie ? Lisez-vous de la poésie contemporaine? Quelle place tient la poésie dans la vie des jeunes que vous connaissez, quelle place a-t-elle tenue dans votre formation? La poésie se trouve-t-elle pour vous uniquement dans les poèmes? Où ailleurs?

2 2. La poésie et la linguistique ont eu, dans l'histoire des cent ans derniers, des rapports, de la connivence, mais quasi marginaux ou clandestins, même si les formalistes russes étaient souvent reconnus comme linguistes lettrés, férus de poésie. R. Jakobson a été par excellence l'héritier de cette tradition. Quant à F. de Saussure, É. Benveniste, E. Coseriu, si mal connu en France, mais présenté à nouveaux frais dans cette livraison, on découvre étape par étape - avec même un accelerando - que la poésie a joué un rôle dans leurs recherches linguistiques. Ce dernier, longtemps considéré comme insignifiant, est en effet en perpétuelle réévaluation (citons par exemple les travaux sur F. de Saussure synthétisés dans le Saussure [S. Bouquet, dir., Paris, Éd. de l'Herne 2003], ceux consacrés à É. Benveniste par G. Dessons [Émile Benveniste, l'invention du discours, Paris, In Press, 2006] et C. Laplantine [Émile Benveniste, l'inconscient et le poème, Limoges, Lambert-Lucas, 2011], et enfin l'intérêt manifesté par F. Rastier et F. Neveu pour E. Coseriu. De votre côté, que pensez-vous de ce rôle de la poésie dans la réflexion linguistique de ces trois grands linguistes ? Faut-il y ajouter un quatrième, psychanalyste-linguiste, J. Lacan? En quoi estce que la mise au jour (et à jour) de ce rôle de la poésie transforme le paysage de ces œuvres fondamentalement linguistiques, mais à dimension anthropologique ? Et que nous dit cette réévaluation progressive des chemins et enjeux de la linguistique aujourd'hui?

3 3. Dans quels domaines de la linguistique la poésie permettrait-elle d'ouvrir des perspectives nouvelles? Dans la syntaxe ? S. Mallarmé pensait que le poète était avant tout un syntacticien. Dans la syntaxe standard? Ou doit-on faire une place aux syntaxes 
d'autres types, syntaxe prosodique, syntaxe visuelle ou picturale au sein d'une linguistique élargie des discours, comme semble le suggérer G. Dessons? C. BlancheBenveniste refusait de parler alors de syntaxes, préférant le mot de structurations...

4. Dans la sémantique? Car ces différents types de structuration de la poésie amènent à une sémantique, elle-même élargie, une sémantique plurielle, tenant compte d'unités de discours plus diversifiées. $\mathrm{Y}$ auraient toute leur place, syntaxique et sémantique : la phrase, qui ne serait plus l'unité de discours unique du modèle benvenistien; le vers, ou segment "blanchi», selon les travaux sur la poésie visuelle publiés sous la direction d'I. Chol [Livres de poésie, jeux d'espace, Paris, H. Champion, 2016] - et par M. Favriaud [Le plurisystème ponctuationnel français à l'épreuve de la poésie contemporaine, Limoges, LambertLucas, 2014, p. 55-69]; le verset, la période (unité dont on aurait peut-être besoin à l'écrit, en surplus de la phrase et non en substitution [M. Favriaud, id. op., p. 159-165 et 217-225, et article «La phrase déjouée et rejouée dans la poésie contemporaine » in La Langue littéraire à l'aube du XXIe siècle, dirigé par C. Narjoux, Dijon, Presses universitaires de Dijon, 2010, p. 269-280]); et enfin une "unité fluctuante" répondant à la loi jakobsonienne de la "couplaison" - et à celle de la prosodie sérielle défendue par G. Dessons et H. Meschonnic [Traité du rythme. Des vers et des proses, Paris, Dunod, 1988, p. 163-167 notamment]. Ne faut-il pas en effet tenir compte, dans la sémantique d'autres types de textes comme dans celle des poèmes, d'une architecturation, concordante et potentiellement discordante à la fois, d'unités de discours diverses ?

5 5. En suivant cette voie, que j'ai un peu empruntée en essayant de montrer combien la poésie contemporaine peut informer une théorie de la ponctuation et du texte, et l'élargir [op. cit. supra et M. Favriaud, "Le Chat de Schrödinger pris entre plurisystème ponctuationnel et unités discursives", in: S. Pétillon, F. Rinck, G. Antoine, dirs, La Ponctuation à l'aube du XXI siècle. Perspectives historiques et usages contemporains, Limoges, Lambert-Lucas, 2016, p.163-176], pensez-vous que la poésie puisse éclairer d'autres domaines, considérés a priori hors champ de la poésie? Je pense à l'énonciation, par exemple, que M. Monte analyse dans l'œuvre de P. Jaccottet [Mesures et passages. Une approche énonciative de l'œuvre poétique de Philippe Jaccottet, Paris, H. Champion, 2002]. Je pense aussi, sur un autre plan, à la question du récit, qu'on abandonne aux spécialistes de la spécialité, alors que les poéticiens de la poésie auraient peut-être quelque chose à dire sur le temps, le récit, les personnages, le dénouement, etc. pour élargir ces notions...

6 6. Et si poésie et langue (littérature et langue(s) dissociées quasi officiellement dans le colloque de l'association internationale pour la recherche en didactique du français [AIRDF] à Québec, 2004), étaient (ré)conciliées dans une didactique du français qui ne serait plus scindée en deux comme la pensent un certain nombre de didacticiens, la littérature/la langue, quels principes généraux pourrait-on mettre en œuvre au primaire, au secondaire et au supérieur pour mieux accorder ou relier ou stimuler imaginaire et réflexivité sur la langue? Le lien tenté entre les deux dans les années quatre-vingt et quatre-vingt-dix au primaire et au secondaire, a paru échouer dans nombre de cas, avant d'être abandonné en tout ou en partie, d'un côté pour formalisme excessif et grammaires de texte absconses, de l'autre, autour du CP, pour avoir détourné les élèves du système alphabétique et orthographique. Comment reconstruire les bases d'un nouveau mariage, comment faire profiter à la poésie des apports de la linguistique, sans peser trop, et à la réflexion naissante des élèves sur la langue des apports des poèmes, interprétés, dits à haute voix ou créés en atelier d'écriture? On pourrait penser alors à une "main à la pâte» de G. Charpak associée à la poésie... Ce qui voudrait 
probablement dire des enseignants formés autrement. Et pour revenir finalement à S. Mallarmé, l'enjeu de la poésie moderne prise dans sa réception, n'est-il pas la lecture, l'invention d'un nouveau type de lecteur, plus souple, plus complexe, plus généreux, dont la société aurait grand besoin, même hors champ de la littérature ? Programme scolaire et anthropologique, s'il en est !

\section{AUTEUR}

\section{MICHEL FAVRIAUD}

Université Toulouse - Jean Jaurès, LLA-Créatis, EA 4152, F-31000, France 